\title{
Bullying e cyberbullying no ambiente escolar: a utilização de jogos como instrumento de conscientização, prevenção e combate a essas práticas
}

\author{
Karla Michelle de Meneses Caeiro Braga (MPNTDE | UniCarioca) \\ Patrícia M. de Oliveira (MPNTDE | UniCarioca) \\ Paula Jucá de Sousa (MPNTDE | UniCarioca | IFTO) \\ Ana Paula Legey (NUCAP | MPNTDE | UniCarioca) \\ Antônio Carlos Mól (NUCAP | MPNTDE | UniCarioca | IEN | CNEN) \\ Victor Gonçalves Freitas (NUCAP | MPNTDE | UniCarioca) \\ Leonardo Trotta (UniCarioca | SEEDUC-RJ)
}

\section{Resumo}

A violência ocorre de diferentes formas na sociedade e pode ser caracterizada como uma das grandes problemáticas da atualidade. Levando em consideração as abordagens e as características de atos violentos, este artigo visa abordar os fenômenos sociais conhecidos atualmente como bullying e cyberbullying em duas escolas públicas, uma localizada no Rio de Janeiro e outra em Tocantins. O objetivo principal foi averiguar se as tecnologias podem contribuir como instrumento de conscientização, prevenção e combate ao bullying nas escolas. Assim, foi elaborada e aplicada, nas duas instituições, uma sequência didática utilizando o jogo Estrela do Saber elaborado pelo Núcleo de Computação Aplicada da UniCarioca (Nucap) O público-alvo do estudo foram adolescentes da faixa etária entre 14 e 17 anos e cerca de 78 professores. A fim de obter dados, utilizou-se a pesquisa quantitativa, e, para a interpretação destes, empregou-se como base a técnica descritiva. Como resultado, verificou-se que os recursos tecnológicos aliados a metodologias de socialização podem amenizar os índices de violência escolar caracterizados como bullying e cyberbullying.

Palavras-chave: Bullying; Cyberbullying; Violência; Ambiente escolar; Educação.

\begin{abstract}
The present article aims to approach the social phenomenouns currently know as Bullying and Cyberbullying in two public schools, one located in Rio de Janeiro and the other in Tocantins. The main purpose was to find out whether the technologies can contribute as an instrument of awareness, prevention and fight against Bullying in schools. Therefore was developed and applied a didactic sequence using Nucap games in both institutions. Participated if the study teenagers from 14 to 17 years old and about 78 teachers. In order to obtain data was used the qualitative research. For their interpretation the descriptive technique was used. As a result was found that technological resources allied to socialization methodologies can reduce the rates of school violence characterized as Bullying and Cyberbullying.
\end{abstract}

Keywords: Bullying.; Cyberbullying; Violence; School environment ; Education

\section{Introdução}

No Brasil, são comuns estudos que buscam identificar os problemas no ambiente escolar que se refletem nos baixos índices de aproveitamento e têm como uma das consequências resultados insatisfatórios em avaliações de desempenho estudantil realizadas por organismos internacionais e pelo Ministério da Educação (MEC). Para a elaboração deste trabalho, tomamos como base a Pesquisa Nacional de Saúde Escolar (PeNSE), os estudos divulgados na página oficial do Ministério da Educação (MEC) e na do Instituto Nacional de Estudos e Pesquisas Educacionais Anísio Teixeira (INEP), com o intuito de compreender o panorama da violência no ambiente escolar e suas consequências na saúde emocional e no desempenho acadêmico dos alunos. 
$\mathrm{Na}$ análise desses estudos, foi possível identificar que uma parte desse problema de rendimento está ligada a questões sociais, como baixa escolaridade dos pais, violência praticada por organizações criminosas nos arredores da escola, inserção no mercado de trabalho de alunos em idade escolar, problemas ligados à saúde e ao saneamento básico, entre outros.

Segundo Rocha (2012, p. 21), "a violência é um processo dirigido a certos fins, tendo diferentes causas, assumindo formas variadas e produzindo certos danos, alterações e consequências, imediatas ou de longo prazo". A autora analisa de forma bastante contundente os dados que apurou e apresenta como uma das perspectivas de análise a diferença entre violência física e não física, destacando que em ambos os casos as consequências para os alunos são significativas e devem ser observadas, acompanhadas e tratadas pela escola e pela família.

A violência, seja no ambiente escolar, seja fora dele, pode se manifestar por meio de agressões físicas, verbais ou emocionais/sociais. As duas últimas modalidades, por não deixarem marcas visíveis e serem mais difíceis de ser identificadas, dificultam ações por parte da família e da escola, seja qual for o ambiente e o contexto de suas ocorrências. Além de suas consequências prejudiciais na interação social dos alunos e no rendimento escolar, nos casos mais severos a violência leva a atos extremos, como a prática do suicídio ou de violência desferida com arma de fogo contra os colegas.

A violência não física, mas simbólica ou verbal, quando perpetrada reiteradamente, manifesta-se na vítima como um sentimento de inadequação crescente, que muitas vezes leva à depressão, à ansiedade e a outras doenças de caráter emocional ou psicossomático e, em casos extremos, ao suicídio, como pode ser observado não só no texto de Rocha (2012), como também, na entrevista com Isabela Nicastro, que abordaremos adiante e cujos créditos constam nas Referências.

Em um cenário inclusivo e colaborativo, o professor atua predominantemente como um mediador, permitindo que os alunos busquem o conhecimento no material apresentado, em pesquisas on line, em grupos de estudos que permitem a troca de informações entre os estudantes e em trabalhos mediados por ferramentas tecnológicas. Para alcançar os objetivos e obter o engajamento dos alunos, são utilizados diversos métodos e instrumentos, como sala de aula invertida, aprendizagem por projetos, abordagem de temas por meio de trabalhos em grupo, dentre outros. Essas estratégias permitem que os alunos se relacionem de forma mais efetiva entre si e relacionem os conteúdos de forma integrada. Além disso, a colaboração, a inclusão e as metodologias ativas permitem muitas vezes que o professor seja capaz de dedicar um olhar mais atencioso àqueles alunos que apresentam comportamentos "anormais" para a faixa etária do grupo: isolamento, baixa autoestima, infrequência, imaturidade e outros que se configuram no ambiente escolar e que ficam mais visíveis em trabalhos colaborativos. A esse respeito, destacam-se os estudos realizados por Gabriel (2013) e Campos (2003).

No documentário organizado pela Unesco intitulado Violência na escola: América Latina e Caribe, Miriam Abramovay (2003, p. 111) indica que é preciso repensar estratégias de enfrentamento da violência também na escola: "A violência permeia todas as relações sociais e afeta profundamente o cotidiano da comunidade escolar. Por isso, é fundamental construir uma visão crítica sobre o assunto e propor alternativas para superá-la”.

Segundo Rocha (2012), o Bullying é uma expressão da língua inglesa formada por bully (valentão, brigão), acrescida do sufixo ing, que indica ação em andamento, ou seja, pratica bullying aquele que procura exercer o papel de valentão ou brigão, diminuindo sua vítima física ou emocionalmente.

Para identificar o bullying, em linhas gerais, devem estar presentes na agressão três características: o ato violento (que pode ser físico, verbal ou social, como vimos anteriormente); a repetição, ou seja, deve haver certa recorrência, não se caracterizando como bullying os atos isolados, ainda que violentos; e a relação desigual de poder, mesmo que ela não seja real, mas apenas percebida pela vítima.

Esses três aspectos são vistos como centrais, mas a literatura apresenta diversas definições para o bullying. Para Constantini, citado por Rocha (2012, p. 65):

estudantes, mas verdadeiros atos de intimidação preconcebidos, ameaças que, sistematicamente, com violência física ou psicológica, são repetidamente impostos a indivíduos particularmente mais vulneráveis e incapazes de se defenderem, o que leva a uma condição de sujeição, sofrimento psicológico, isolamento e marginalização. 
Por sua vez, Farrington, citado por Rocha (2012, p. 65-66), afirma:

O bullying é uma opressão repetida, de natureza física ou psíquica, de uma pessoa com menos poder por outra com mais poder.

[...] seis elementos centrais da prática de bullying:

Práticas de agressão física, verbal ou psicológica (intimidação).

O agressor é mais poderoso ou, pelo menos, assim é visto pela vítima.

Há intenção de causar medo e/ou dor à vítima.

A agressão não é provocada pela vítima.

As agressões são repetidas.

Os agressores alcançam o resultado desejado.

Do ponto de vista legal, a Lei n. 13.185/2015 apresenta a definição de bullying da seguinte forma:

Art. 1o Fica instituído o Programa de Combate à Intimidação Sistemática (Bullying) em todo o território nacional.

$\S 10$ No contexto e para os fins desta Lei, considera-se intimidação sistemática (bullying) todo ato de violência física ou psicológica, intencional e repetitivo que ocorre sem motivação evidente, praticado por indivíduo ou grupo, contra uma ou mais pessoas, com o objetivo de intimidá-la ou agredi-la, causando dor e angústia à vítima, em uma relação de desequilíbrio de poder entre as partes envolvidas.

[...]

Art. 20

[...]

Parágrafo único. Há intimidação sistemática na rede mundial de computadores (cyberbullying) quando se usarem os instrumentos que lhe são próprios para depreciar, incitar a violência, adulterar fotos e dados pessoais com o intuito de criar meios de constrangimento psicossocial.

A partir das definições acima é possível identificar como característica marcante do bullying a frequência com que a violência é desferida pelo agressor à vítima, gerando um constante estado de alerta e de ansiedade, com consequências prejudiciais ao equilíbrio emocional do estudante e, por consequência, danos às suas habilidades de absorção de conteúdos e de interação social.

O cyberbullying, por sua vez, diferencia-se do bullying pelo canal utilizado para efetivar as agressões e pelo alcance dos seus resultados. Nessa modalidade de violência, as agressões são difundidas por meio de aplicativos, redes sociais, e-mails ou outro canal eletrônico. Apesar de não ser realizado pessoalmente, seus efeitos são devastadores, na medida em que o material disponibilizado na internet se propaga rapidamente. Além disso, o anonimato encoraja muitos agressores e dificulta qualquer tipo de atitude por parte da vítima, tornando essa violência bastante devastadora, sobretudo quando envolve questões vexatórias ou atos de cunho sexual:

O potencial multiplicativo das mensagens disparadas por meio de tecnologias revela o caráter repetitivo desta prática. A repetição não depende apenas de um único autor para acontecer, pois, na medida em que cai em rede, sua autoria, amplitude e audiência são caracterizadas pela comunicação horizontalizada, todos com todos; as mensagens são compartilhadas, manipuladas, reproduzidas com rapidez e comodidade. (ROCHA, 2012, p. 83-84).

Não se trata de atribuir graus de severidade para cada uma das práticas, bullying e cyberbullying, mas apenas de diferenciar suas características para que o leitor possa compreender melhor seus impactos e, assim, construir os processos de prevenção e combate ou colaborar com eles.

Para efeito deste trabalho, será chamado genericamente de bullying as ocorrências que se encaixam nas características que descreveremos adiante, ainda que praticadas em meio digital (cyberbullying). Apenas quando for imprescindível a diferenciação será usado especificamente o termo cyberbullying. 
Para abordar o assunto, será exposto uma sugestão de sequência didática, que inclui a utilização de jogos desenvolvidos pelo Núcleo de Computação Aplicada (Nucap) da UniCarioca. Desta forma, será apresentado o questionário que foi desenvolvido para inserção no jogo, bem como a pesquisa que foi realizada com os professores dos estados do Rio de Janeiro e do Tocantins, e a sequência didática aplicada com o intuito de averiguar se eles consideram que as tecnologias podem ser um instrumento de auxílio na prevenção e no combate ao bullying e se as perguntas no formato de jogo são interessantes para abordar o tema em sala de aula. Em seguida, faremos uma análise das características do jogo Estrela do Saber para identificar se este é adequado para a finalidade de trabalhar de forma lúdica e interativa o tema.

Nosso intuito durante a pesquisa foi delinear instrumentos ou aplicar os já existentes com o objetivo de não só demonstrar a professores e a alunos a relevância do tema como também incentivá-los a abordá-lo em sala de aula para gerar uma melhor compreensão dos alunos acerca do assunto, como forma de conscientização a respeito das práticas de bullying.

\section{Métodos}

Os autores inicialmente analisaram a literatura sobre o bullying e o cyberbullying, com o intuito de compreender os conceitos que norteiam o tema.

Posteriormente, foi realizado um estudo das últimas pesquisas sobre o assunto, realizadas sobretudo pelo Ministério da Educação (MEC), pelo Instituto Brasileiro de Geografia e Estatística (IBGE) e pelo Instituto Nacional de Estudos e Pesquisas Educacionais Anísio Teixeira (INEP).

Após uma compreensão mais profunda acerca desses dados, as autoras elaboraram um questionário, que foi aplicado aos professores de duas escolas públicas, uma localizada no Rio de janeiro e outra em Tocantins . A escolha de duas escolas de estados distantes e com perfis diferentes (uma de ensino fundamental e outra de ensino médio) foi proposital, pois a intenção era de comparar os resultados obtidos para verificar se seriam ou não semelhantes quando abordado o tema da violência escolar.

Em seguida, as autoras, em parceria com o Núcleo de Computação Aplicada (NUCAP) do Centro Universitário Carioca (UniCarioca), situado no Rio de Janeiro, elaboraram perguntas para um jogo desenvolvido pelo núcleo, com o objetivo de aplicá-lo em sala de aula e então analisar as respostas dos alunos, bem como o engajamento deles com o tema e a visão acerca das práticas de bullying e cyberbullying nas escolas.

As respostas foram compiladas e geraram gráficos que apresentaram o panorama da incidência e da percepção pelos alunos das práticas violentas no âmbito escolar.

Por fim, para avaliar a capacidade dos alunos em transformar suas percepções, conceitos e dúvidas em questionamentos, os professores envolvidos na aplicação deste instrumento em sala de aula permitiram que fossem inseridas novas perguntas no jogo, formuladas ao final da sequência didática utilizada em sala de aula para trabalhar o tema.

Neste artigo, abordaremos de forma mais detalhada a dinâmica do trabalho desenvolvido nas escolas selecionadas no tópico Sequência Didática, além de analisarmos de forma mais minuciosa os resultados obtidos e as discussões resultantes do processo implementado nos itens a seguir.

\section{Resultados e discussão}

\section{A pesquisa realizada com os professores}

Considerando que a instituição escolar auxilia na formação do caráter do indivíduo e que esta pode proporcionar momentos de debates e desenvolver ações que contribuam para a mudança e a conscientização dos discentes, é que se propõe esta pesquisa. A priori, levou-se em consideração o papel do professor, pois é ele que atua diretamente com o educando, podendo detectar, interagir e promover ações que amenizem esse tipo de violência.

Para fins de análise, o instrumento utilizado foi um questionário on line aplicado aos professores de duas instituições 
públicas de ensino, uma localizada no Rio de Janeiro e outra no Tocantins, com o intuito de conhecer a concepção dos educadores referente aos casos de bullying e cyberbullying nos ambientes em que estes estão inseridos e as práticas desenvolvidas nesses espaços. O roteiro do questionário foi composto de nove questões norteadoras. As primeiras perguntas eram referentes à identificação dos casos de bullying no ambiente escolar e as demais abordavam a concepção do educador em utilizar as tecnologias e se as perguntas propostas para o jogo poderiam ser um instrumento de conscientização, prevenção e combate a esse tipo de violência.

O questionário contou com a participação de 78 professores, com $59 \%$ atuando no Rio de Janeiro e $41 \%$ em Tocantins. Os professores participantes do Rio de Janeiro atuam nas redes municipais e/ou estaduais das cidades de Magé, Duque de Caxias e do Rio de Janeiro e atuam com alunos do ensino fundamental. A instituição do Tocantins pertence à rede federal de ensino, atende alunos do ensino médio integrado ao técnico e está localizada a $12 \mathrm{~km}$ da cidade de Paraíso do Tocantins, sendo considerada uma escola interiorana.
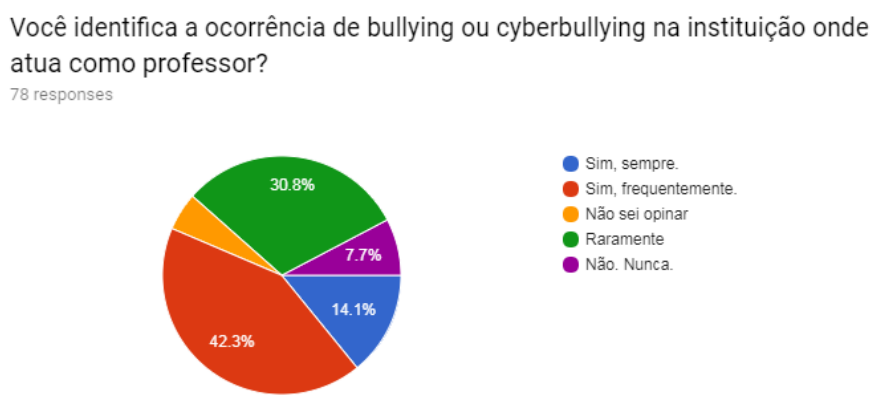

- Sim, sempre.

Gráfico 1. Identificação de ocorrência de bullying e cyberbullying

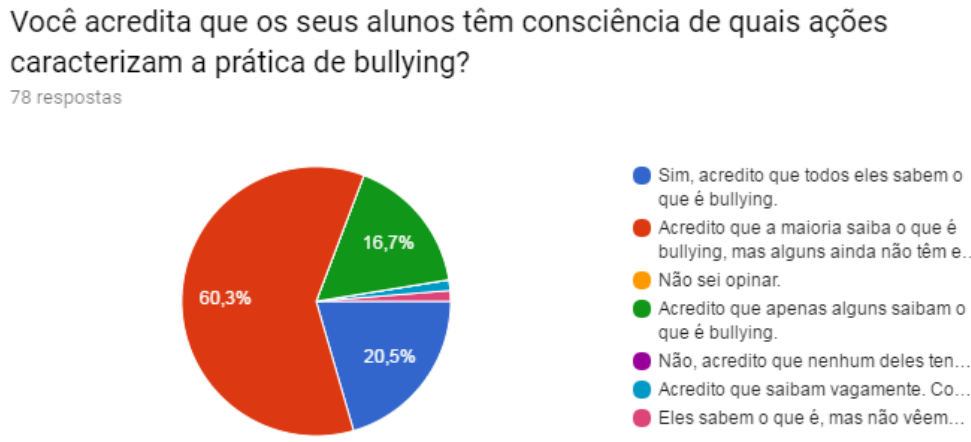

Gráfico 2. Ações que caracterizam o bullying

Mais de $60 \%$ dos professores que responderam ao questionário acreditam que a maioria dos alunos saiba o que é bullying, contra apenas $16,7 \%$ que acreditam que apenas alguns saibam o que isso significa. Analisando as duas primeiras perguntas conjuntamente, verifica-se que os professores identificam a prática e que os alunos sabem o que caracteriza o bullying.

Com base nessas duas questões, é possível aferir que os atos de violências que caracterizam o bullying são praticados de forma intencional, visto que a ocorrência é verificada e os alunos conseguem identificá-la.

Sendo assim, não se pode resolver um problema que surge a partir de atos violentos intencionais praticados por alunos, sem que haja conscientização sobre suas consequências e sem trabalhar sua prevenção. Desse modo, para reduzir a violência, a escola precisa promover atividades que estimulem o surgimento de vínculos entre alunos, valorizando a afetividade e as relações interpessoais sadias, como destacam diversos autores que abordaram o tema, entre eles ASSIS (2010) e BEAUDOIN (2006). 

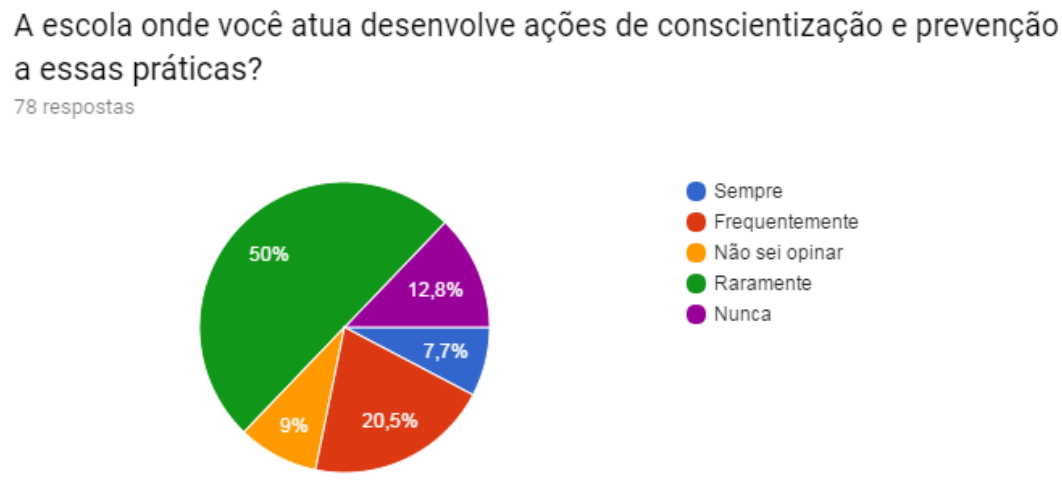

Gráfico 3. Ações de conscientização e prevenção ao bullying

Esse questionamento demonstra que, dos 78 professores, 50\% indicam que a escola em que atua raramente desenvolve ações para conscientização e prevenção do bullying. Apesar da importância do assunto, referida inclusive na Lei Federal n. 13.185 de 09/02/2016, e das ações promovidas pelo Ministério Público em diferentes estados como o programa 'Conte até 10', o que se verifica é que o tema ainda não é abordado com a frequência necessária e que não recebe a atenção devida.

A escola onde você atua age efetivamente quando identifica a ocorrência de bullying realizada por um aluno ou ... o de alunos contra outro aluno/grupo? 78 respostas

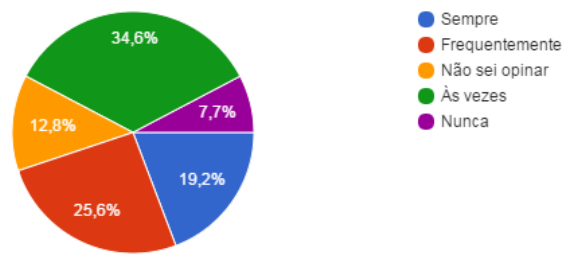

Gráfico 4. Atitudes efetivas contra o bullying

Quanto a agir efetivamente ao identificar o bullying, a maior parte dos professores, $34,6 \%$, indicou que a escola às vezes tem a iniciativa, $25,6 \%$ frequentemente e 19,2\% sempre age efetivamente.

Você acredita que seria fácil identificar que um aluno da sua classe está sendo isolado pelos colegas? 78 respostas
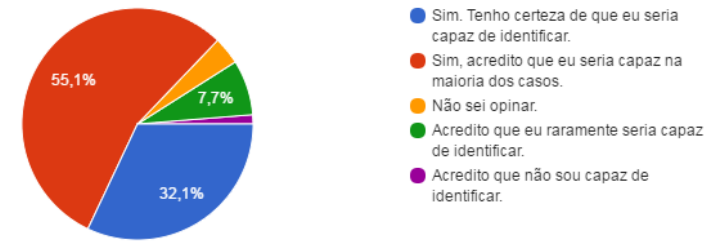

Gráfico 5. Identificação de isolamento de aluno 
Na maioria dos casos, os professores responderam serem capazes de identificar que um aluno está sendo isolado pelos colegas, o que revela um olhar atento dos profissionais quanto ao comportamento em sala de aula, levando-se em consideração não apenas as questões cognitivas do aluno, mas também as emocionais.

Você acredita que seus alunos têm facilidade para lidar com recursos tecnológicos?

79 respostas

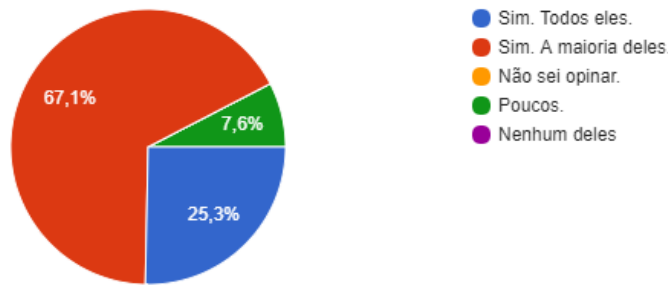

Gráfico 6. Alunos com facilidade de lidar com recursos tecnológicos

Como pode ser observado, quase 70\% dos professores relatam que seus alunos têm facilidade com os recursos tecnológicos, uma vez que a tecnologia permeia as sociedades e que os alunos na faixa etária dos 14 aos 17 anos são considerados nativos digitais. Contudo, de acordo com os dados da pesquisa, apenas 7,8\% indicam que poucos discentes não têm facilidade para lidar com recursos tecnológicos. Os outros $92,2 \%$ têm facilidade de trabalhar com recursos tecnológicos, percentual expressivo e que não pode ser ignorado.

\section{Você se considera apto a introduzir recursos tecnológicos em suas aulas? 79 respostas}

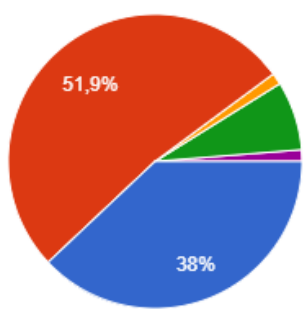

Sim. Totalmente apto.

Acredito que sim, para muitos

recursos.

Não sei opinar

Lido bem com poucos recursos.

Não sei usar recursos tecnológicos.

Gráfico 7. Professores aptos para introduzir recursos tecnológicos nas aulas

Observa-se que 38\% dos professores declaram-se totalmente aptos a introduzir os recursos tecnológicos em suas aulas, embora seja do conhecimento geral que a educação ainda traz muito dos métodos tradicionais, com aulas expositivas e com a implementação de novos recursos na aprendizagem ainda ocorrendo de maneira muito tímida, sem uma política pública eficaz. Mais de 50\% dos professores acreditam que estariam aptos a implementar elementos de tecnologias em seus planejamentos, embora os alunos se queixem com frequência de que as aulas são paradas e monótonas. 

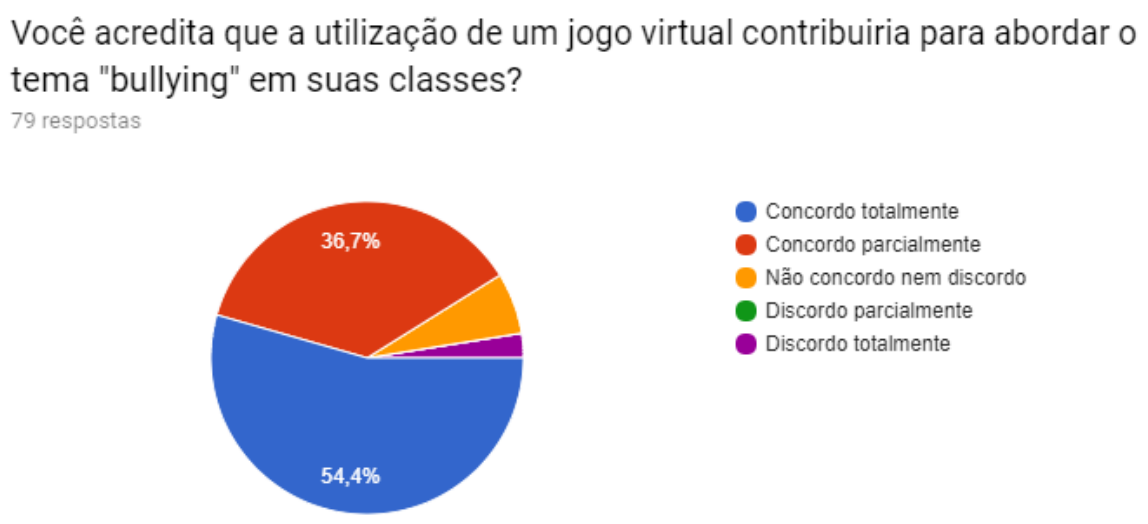

Gráfico 8. Contribuição de jogo virtual para abordar o tema bullying

Na pergunta 8, no entanto, questionamos se um jogo virtual contribuiria para a abordagem do tema bullying em sala de aula. As respostas a essa pergunta guardaram coerência com o que foi verificado nas respostas à pergunta 7, na qual os professores afirmaram que dominam recursos tecnológicos quase sempre ou sempre. Sendo assim, a maioria dos professores $(54,4 \%)$ acredita que o jogo virtual contribuiria para abordar o tema bullying em suas classes.

Apesar disso, quase 40\% dos professores concordaram parcialmente que jogos virtuais podem ser incluídos como um recurso para trabalhar a temática bullying nas aulas.

Em seguida, perguntamos se eles acreditavam que as perguntas que propusemos para o jogo contribuiriam para a adoção dessa prática pedagógica para os estudantes. A maior parte dos entrevistados respondeu que sempre ou em muitos casos, mas chama a atenção uma quantidade expressiva dos que não souberam opinar. Atribuímos isso à possível falta de prática com instrumentos eletrônicos/digitais, que pode inibir a adoção de jogos digitais em suas aulas, bem como de outros recursos digitais.

\section{Você considera que as perguntas propostas no arquivo anexo para o jogo Tabuleiro Virtual contribuiriam para ab...r, prevenir e combater essas práticas? 79 respostas}

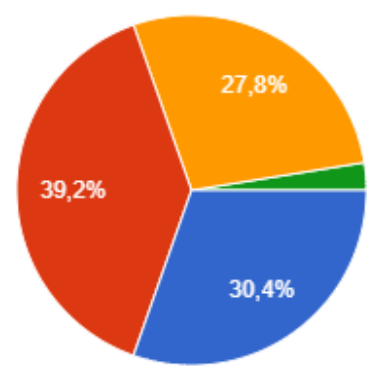

Sim, concordo que contribuiriam.

Concordo que contribuiriam em muitos casos.

Não sei opinar.

Contribuiriam em poucos casos.

Não contribuiriam.

Gráfico 9. Contribuição das perguntas do jogo para combater o bullying 
No grupo de professores, $39,2 \%$ concordam que as perguntas contribuiriam em muitos casos para conscientizar, prevenir e combater a prática de bullying no ambiente escolar, o que evidencia a relevância de implementação dos recursos tecnológicos no fazer pedagógico, sobretudo na abordagem de temas complexos, pois atrela a ludicidade, a tecnologia e as necessidades de construção de sujeitos críticos.

Além disso, 30,4\% concordam que sim, ou seja, colaboram para explorar a temática nas aulas perpassando por diferentes áreas do conhecimento do currículo. Ou seja, esses números reforçam a viabilidade de se discutir no ambiente escolar temas complexos, com o apoio da tecnologia e das práticas lúdicas.

\section{Em qual Estado você trabalha? \\ 79 respostas}

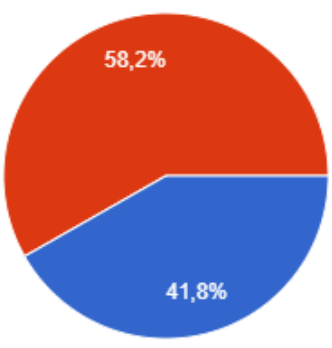

Tocantin

Rio de Janeiro

Gráfico 10. Estado de atuação do professor

Observa-se que 58,2\% dos professores entrevistados atuam em escolas do Rio de Janeiro e 41,8\%, em Tocantins.

$\mathrm{Na}$ análise contextualizada das perguntas, fica evidenciado que o debate do tema em sala de aula é urgente e necessário e que ações dos professores, inclusive envolvendo material digital e lúdico, são atitudes importantes na busca da redução desses atos de violência.

\section{As perguntas inseridas nos jogos do Nucap}

O Centro Universitário Carioca (UniCarioca) possui um laboratório de tecnologias digitais, Nucap, que dá suporte, entre outros cursos, ao de Mestrado em Novas Tecnologias Digitais na Educação, do qual as autoras são alunas. O objetivo do núcleo é desenvolver uma série de jogos visando permitir que os professores possam utilizar os recursos tecnológicos para enriquecer suas aulas, tornando o aprendizado mais lúdico e criativo.

Os jogos educativos podem contribuir de maneira significativa, pois agregam um caráter lúdico à atividade, propiciando desafios, estabelecendo relações, possibilitando o confronto de hipóteses, de erros e de acertos e criando estratégias para aprendizagens significativas.

A educação cada vez mais apresenta desafios, e as novas tecnologias podem contribuir para o processo de ensino-aprendizagem, tornando as aulas mais dinâmicas e colaborativas. Masseto enfatiza a importância da tecnologia no processo ensino-aprendizagem:

A tecnologia reveste-se de um valor relativo e dependente desse processo. Ela tem sua importância apenas como um instrumento significativo para favorecer a aprendizagem de alguém. Não é a tecnologia que vai resolver ou solucionar o problema educacional do Brasil. Poderá colaborar, no entanto, se for usada adequadamente, para o desenvolvimento educacional de nossos estudantes. (MORAN; MASSETO; BEHRENS, 2000 p. 139)

Na Era Digital, entendemos que a utilização de recursos tecnológicos torna o processo de discussão do tema mais dinâmico, atrativo e colaborativo, além de estar mais adequado à linguagem dos alunos, conforme salienta Gabriel (2013). 
Assim, optamos pelo Jogo Estrela do Saber construído pelo Nucap, no qual há um caminho a ser percorrido e diversas perguntas que permitem a conclusão do trajeto. Escolhemos esse jogo por entender que estava adequado para trabalhar com alunos com idade entre 14 e 17 anos nas escolas mencionadas anteriormente, situadas no Rio de Janeiro e em Tocantins.

Foram elaboradas vinte perguntas abordando a questão do bullying em situações práticas, nas quais os alunos deveriam identificar sua ocorrência e indicar as ações adequadas para evitá-lo ou combatê-lo.

O jogo Estrela do Saber possui um cenário lúdico e interativo, em que o personagem deve seguir o percurso respondendo a perguntas. Neste sentido, permite que o jogador (aluno) conclua a trajetória e atinja o objetivo final.

As perguntas do jogo Estrela do Saber foram elaboradas levando-se em consideração a temática do bullying, de maneira que permita uma reflexão sobre o comportamento dos alunos no cotidiano escolar no que diz respeito às atitudes corriqueiras nos diferentes espaços da escola. O objetivo é conscientizar acerca dos impactos dessa prática, evitar novas ocorrências e inibir a continuidade de atitudes violentas, tornando o ambiente escolar mais harmonioso.

O jogo Estrela do Saber constitui-se de um cenário 'em mundo aberto' em que o aluno poderá escolher um avatar (pequeno boneco que o representa no jogo). O objetivo é chegar até a Estrela do Saber, que representa o conhecimento. Para isso, o aluno terá de encontrar as 'chaves' escondidas pelo cenário e responder corretamente a uma pergunta para cada chave, passando por alguns desafios durante o percurso.

O jogo tem como características motivar e estimular o desenvolvimento de estratégias para resolução de problemas, exercitar a tomada de decisões rápidas, requerer a participação ativa e permitir maior interação entre os alunos com o objetivo comum de conseguir descobrir as 19 chaves e alcançar a Estrela do Saber, ou seja, o conhecimento.

Figura 1. Tela inicial d

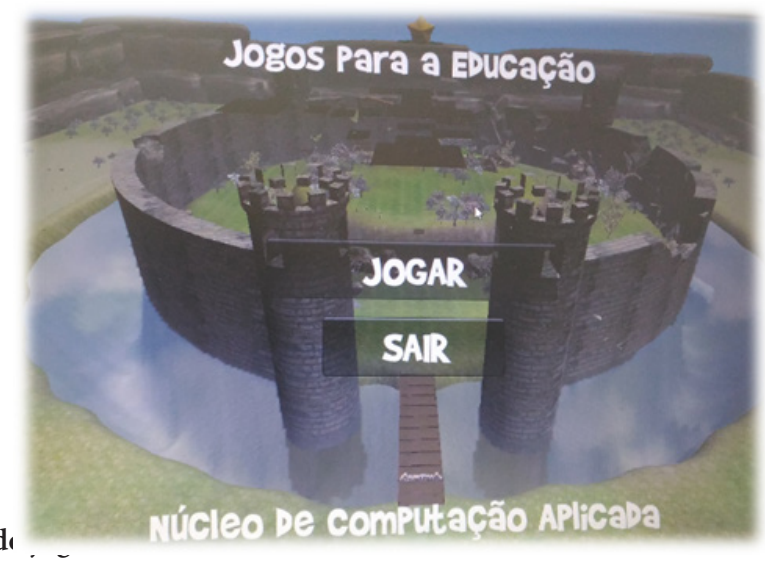

Figura 2. Escolha do

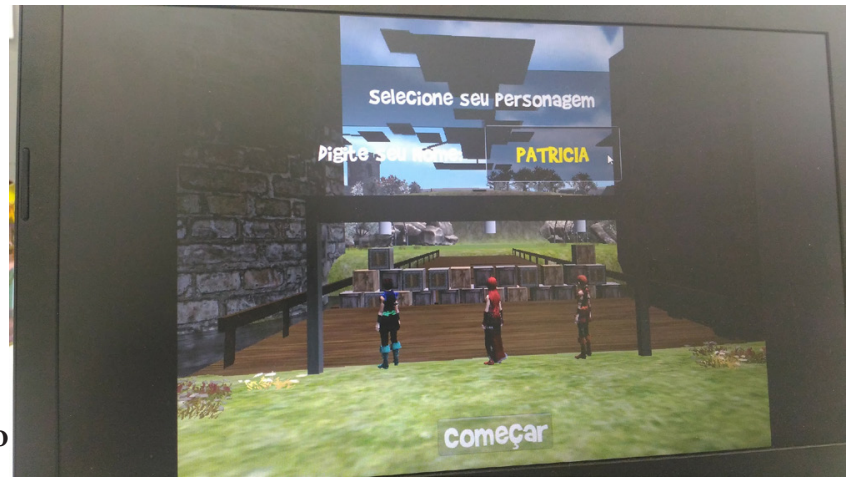




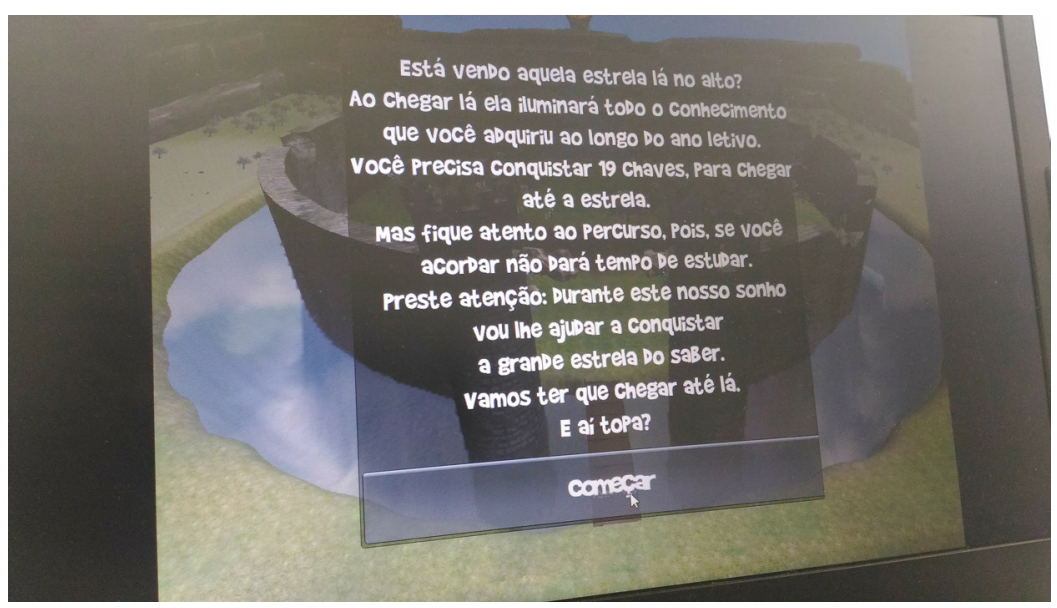

Figura 3. Instruções para o jogo Estrela do Saber.

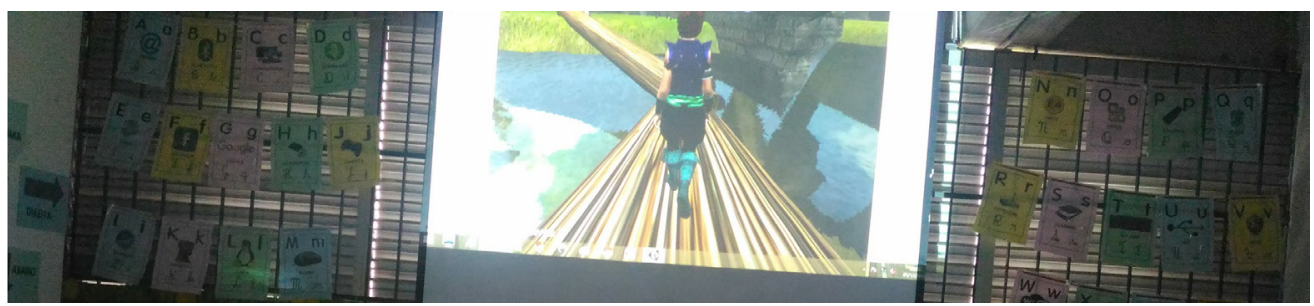

Figura 4. Trilha para chegar à Estrela do Saber

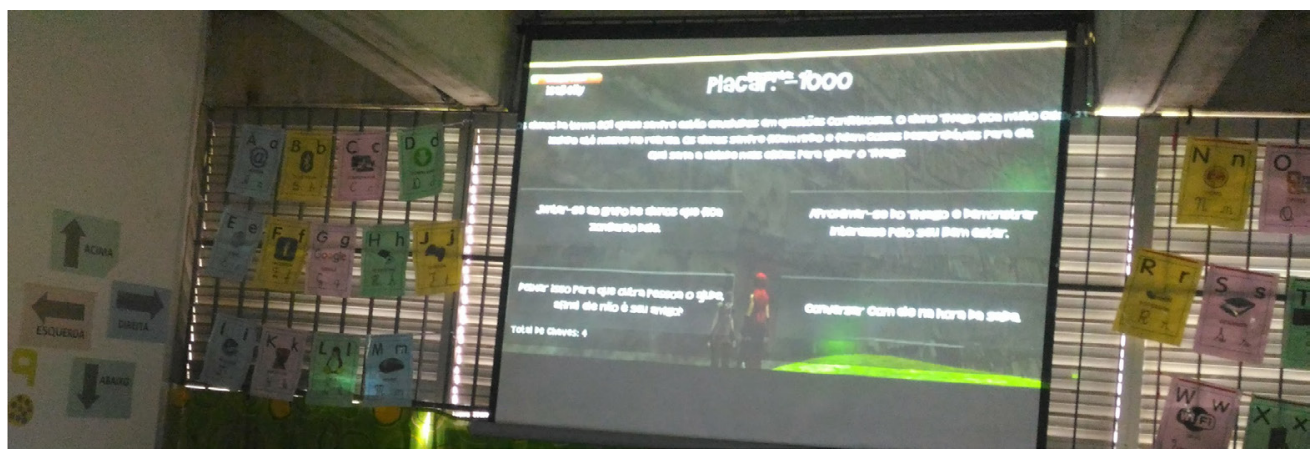

Figura 5. Tela que aparece ao encontrar uma pergunta 


\section{Sequência didática}

Após análise dos dados, foi proposta às duas instituições a aplicação de uma sequência didática em turmas com adolescentes na faixa etária de 14 a 17 anos. O objetivo dessa etapa foi averiguar se os recursos tecnológicos podem contribuir de forma significativa para a conscientização e a prevenção ao bullying e ao cyberbullying. Desse modo, descrevemos de forma sucinta e detalhada as orientações aos professores, que se dispuseram a contribuir com o trabalho.

Tendo em vista a importância da abordagem do assunto em sala, a proposta da primeira etapa era apresentar uma breve explanação oral sobre a temática, com apoio de textos.

Na segunda etapa, os alunos assistiram ao vídeo Serginho Groisman entrevista Isabela Nicastro. O vídeo apresenta o relato da adolescente que foi alvo de cyberbullying pelos colegas da escola. Foi criado um Fotolog da aluna com ofensas gratuitas a Isabela, que na sala de aula percebia risos e deboches. Como consequência, a aluna deixou de gostar de ir para a escola, contudo conseguiu superar tudo com a ajuda dos pais depois de denunciar o bullying. Em pequenos grupos, promoveuse a discussão sobre o material trabalhado na etapa 1 (debates e textos) e sobre o vídeo da etapa 2 (Serginho Groisman entrevista Isabela Nicastro).

Nesta etapa, pretendeu-se identificar o posicionamento dos educandos diante do tema exposto. Sendo assim, foi realizada uma pequena plenária, debatendo os tópicos abordados nos grupos, sendo imprescindível que o professor mantivesse uma postura neutra, não apresentando seu posicionamento acerca do assunto, mas apenas levantando questões para a reflexão conjunta da turma. O objetivo era identificar os fatores que, na visão dos estudantes, ocasionam a violência e de que forma esta ocorre no ambiente onde convivem.

Na terceira etapa, foi proposta a utilização do jogo Estrela do Saber, produzido pelo Nucap. Em duplas, os alunos tiveram a oportunidade de conhecer as questões elaboradas pelas pesquisadoras por meio de um jogo em Realidade Virtual. O intuito era de que o jogador concluísse o percurso respondendo às questões referentes às práticas e à conscientização do bullying.

Para finalizar a sequência didática, tomamos por base as concepções da teoria sociointeracionista de Vygotsky, que diz que o homem constrói sua história por meio das relações que estabelece com os outros. Rego (1995, p. 56) afirma nesta teoria que "construir conhecimentos implica uma ação partilhada, já que é através dos outros que as relações entre sujeito e objeto de conhecimento são estabelecidas". Nesse viés, sugerimos que, após o entendimento das duplas acerca dos objetivos das discussões e do jogo, estas elaborassem em conjunto novas perguntas sobre bullying, com base no que acreditavam ser mais pertinentes para consolidar o tema, e que estas fossem incluídas no jogo, visto que ele permite a edição das perguntas pelos estudantes.

Finalizada esta tarefa, disponibilizamos um momento para que houvesse a troca de informações, e cada um pôde conhecer as concepções do outro por meio das perguntas elaboradas pelos grupos.

\section{Considerações finais}

Ao propormos a temática da violência nas escolas, nosso intuito foi investigar as ações promovidas pelas instituições escolares e como as tecnologias poderiam auxiliar na conscientização, no controle e no combate ao bullying. Sendo assim, a proposta de utilizar duas escolas de estados diferentes (Rio de Janeiro e Tocantins) foi intencional, no sentido de identificar se havia ocorrências desse tipo de violência e se as dificuldades de abordagem do tema eram semelhantes.

Por meio dos estudos, percebemos que tanto os índices de violência quanto os obstáculos enfrentados pelas instituições são semelhantes. Observamos que a maioria dos professores e dos alunos conseguem identificar os atos de violência, no entanto tornam-se omissos em relação aos fatos. Podemos, então, considerar que essas atitudes podem estar relacionadas às questões culturais e sociais, tendo em vista que ainda vivenciamos os aspectos da escola tradicional, onde o papel do professor é a transmissão de conteúdo, sendo o aluno um mero receptor, como destaca Espíndola (2016).

Assim, consideramos que é urgente que a escola promova ações que amenizem esses comportamentos no ambiente escolar, pois é nesse espaço que o indivíduo tem acesso a informações, discussões e transformações. 
De acordo com Silva (2010), a ação das escolas perante o assunto ainda está em fase embrionária, pois a grande maioria desconhece, omite-se, acomoda-se ou nega a existência do bullying. Por isso, reforçamos que "de maneira prática e objetiva, a escola deve procurar meios para se informar sobre as formas que possibilitem saber quais são as experiências e os sentimentos que seus alunos possuem em relação ao bullying" (Silva, 2010, p. 163).

No entanto, apesar da quase inexistência de ações relacionadas à prevenção e à conscientização ao bullying, ao propormos a sequência didática, os educadores dispuseram-se a colaborar e reconheceram que a sugestão é de extrema importância para a mudança social e cultural da comunidade escolar.

Outra consideração importante foi o fato de envolver as tecnologias para o incremento do assunto. É inegável que estas fazem parte do nosso cotidiano e que, se usadas de forma adequada, podem contribuir de maneira significativa para $o$ desenvolvimento crítico e construtivo dos estudantes. Quando na sequência didática os educandos puderam aplicar os conhecimentos adquiridos no jogo e inserir perguntas, estudar o tema se tornou mais divertido, trabalhando com os alunos a colaboração e tornando a aprendizagem mais significativa.

As tecnologias se estabelecem como mais um espaço de interação para o desenvolvimento dos sujeitos, mas com um diferencial: é um lugar das inteligências dispersas no tempo e no espaço, em que a construção do conhecimento pode acontecer livremente, em uma dinâmica reticular e colaborativa.

Durante a pesquisa, pudemos constatar que para obter resultados relevantes é necessário que as instituições promovam projetos que abordem o tema e que proporcionem momentos de discussão entre a comunidade escolar, os professores e os estudantes. Além disso, para que as ferramentas tecnológicas possam auxiliar nesse processo, é imprescindível que haja engajamento do professor.

Costantini (2004) reforça que devemos proporcionar a escuta e a empatia, estimular o diálogo, estabelecer relações em contextos afetivamente significativos para o desenvolvimento da reflexão crítica, incentivando a participação dos educandos. Segundo Costantini (2004, p. 21-22).

[...] não há respostas infalíveis e cem por cento eficazes; ninguém tem uma varinha de condão, mas, sim, propostas de intervenção, cujos efeitos já foram experimentados em várias ocasiões, que podem ser usadas ou não para enfrentar uma relação mais difícil.

Ressalta-se ainda que a possibilidade de utilização de jogos digitais e a ressignificação de ferramentas podem contribuir de forma considerável para a conscientização, a prevenção e o combate ao bullying e ao cyberbullying no ambiente escolar.

\section{Referências bibliográficas}

ABRAMOVAY, Miriam. Enfrentando a violência nas escolas: um informe do Brasil. Violência na escola: América Latina e Caribe. Brasília: Unesco, 2003. $480 \mathrm{p}$.

ALVES, Francisco Edson. Lei federal já em vigor cria ações para prevenir o bullying. Disponível em:

<http://odia.ig.com.br/rio-de-janeiro/2016-02-22/lei-federal-ja-em-vigor-cria-acoes-para-prevenir-o-bullying.html>. Acesso em: 3 dez. 2017.

ASSIS, Simone Gonçalves de; MARRIEL, Nelson de Souza Motta. Impactos da violência na escola. Sciellos Book. Rio de janeiro: Fiocruz, 2010.

BEAUDOIN, Nathalie, TAYLOR, Mauren. Bullying e desrespeito: como acabar com essa cultura na escola. Tradução de Sandra Regina. Porto Alegre: Artmed, 2006.

BOZZA, Thais Cristina Leite; VINHA, Telma Pileggi. Quando a violência virtual nos atinge: os programas de educação para a superação do cyberbullying e outras agressões virtuais. RIAEE - Revista Ibero-Americana de Estudos em Educação, v. 12, n. 3, p. 1919-1939, jul./set. 2017.

CAMARGO, Orson. Bullying. Disponível em: <http://brasilescola.uol.com.br/sociologia/bullying.htm>. Acesso em: 3 dez. 2017.

CAMPOS, Fernanda C. A.; SANTORO, Flávia Maria; BORGES, Marcos R. S. Cooperação e Aprendizagem On-line. DP\&A Editora: São Paulo, 2003.

CÂNDIDO, Miriam Jussara; OLIVEIRA, Dimas de. TICs como ferramentas motivadoras para introdução do conteúdo "Lutas nas aulas de Educação Física escolar no contexto Luta não é briga". Revista Tecnologias na Educação, ano 7, n. 12, jul. 2015.

CHALITA, G. B. I. Educação: a solução está no afeto. São Paulo: Gente, 2008.

CONSTANTINI, Alessandro. Bullying - Como Combatê-lo?. Itália Nova Editora, 2004.

FANTE, C. Fenômeno bullying: como prevenir a violência nas escolas e educar para a paz. 2. ed. Campinas: Veros, 2005.

. Bullying no ambiente escolar. Revista de Educação Física n. 13, dez. 2008. 
. Bullying escolar: Programa de Enfrentamento ao Bullying no Ambiente Escolar. Campanha Aprender Sem Medo, 2009.

ESPÍNDOLA, Rafaela. Principais tendências da Educação à distância. Disponível em <https://www.edools.com/tendencias-educacao-a-distancia/> . GABRIEL, Martha. Educ@r: a (r)evolução digital na educação. São Paulo: Saraiva, 2013.

MELO, Maria Eugenia Moreira de; ALVES, Luiz Roberto Alves. Radionovelas educativas: na difusão de uma cultura de enfrentamento da violência sexual da criança e do adolescente. Disponível em: <http://www.radiomargarida.org.br/wp-content/uploads/artigo-eugenea.pdf>.

MORAN, José Manuel; MASSETO, Marcos T.; BEHRENS, Marilda Aparecida. Novas tecnologias e mediação pedagógica. Campinas: Papirus, 2000.

MORO, M. L. F. Crianças com crianças aprendendo: interação social e construção cognitiva. Cadernos de Pesquisa, n. 79, p. $31-43$, nov. 1991.

PERRENOUD, P. Dez novas competências para ensinar. Porto Alegre: Artmed, 2000. 162p.

PIMENTEL, Tatiana. Tecnologia parceira no combate à violência. Disponível em: <http://www.impresso.diariodepernambuco.com.br/app/noticia/ cadernos/economia/2017/06/24/interna_economia,170737/tecnologia-parceira-no-combate-a-violencia.shtml>. Acesso em: 3 dez. 2017.

PINHEIRO, Fernanda Martins França; WILLIAMS, Lúcia Cavalcanti de Albuquerq. Violência intrafamiliar e relação entre colegas no ensino fundamental. Cadernos de Pesquisa, São Paulo, v. 39, n. 138, p. 995-1018, set./dez. 2009.

PINTO, Marisa. Cyberbullying: O que é? Como combater? Disponível em: <http://pplware.sapo.pt/informacao/cyberbullying-o-que-como-combater/>. Acesso em: 3 dez. 2017.

PRIOTTO, Elis Palma; BONETI, Lindomar Wessler. Violência escolar: na escola, da escola e contra a escola. Rev. Diálogo Educ., Curitiba, v. 9, n. 26, p. 161-179, jan./abr. 2009.

REGO, T C. Vygotsky - Uma Perspectiva Histórico-cultural da Educação. Petrópolis, RJ: Vozes, 1995.

ROCHA, Telma Brito. Cyberbullying: ódio, violência virtual e profissão docente. Brasília: Liber Livro, 2012.

RODRIGUES, Paloma Alinne Alves et al. Violência na escola: diga não! Disponível em: <http://portaldoprofessor.mec.gov.br/fichaTecnicaAula.html?aula=20795 > . Acesso em: 3 dez. 2017.

RODRIGUES, Paloma Alinne Alves; DOSCHER, Andréa Leão; DOSCHER, Erwin. Bullying e violência contra a pessoa com deficiência. Disponível em: <http://portaldoprofessor.mec.gov.br/fichaTecnicaAula.html?aula=23200>. Acesso em: 3 dez. 2017.

SILVA, Ana Beatriz Barbosa. Bullying - Mentes Perigosas Nas Escolas. Principium Editorial. 2a Ed. 2015.

ZABATEL, Corbo E. (1999). Mediación: cambio social o más de lo mismo? In F. Brandoni (Ed.). Mediación escolar. Propuestas, reflexiones y experiencias. Buenos Aires: Paidós.

Pesquisas educacionais utilizadas:

Página Oficial do Instituto Nacional de Estudos e Pesquisas Educacionais Anísio. Teixeira - INEP. Disponível em:

http://portal.mec.gov.br/dmdocuments/relatoriofinal.pdf

Página Oficial do Ministério da Educação - MEC

http://portal.mec.gov.br/component/tags/tag/34487

Pesquisa Nacional de Saúde do Escolar (PeNSE). Disponível em:

https://biblioteca.ibge.gov.br/visualizacao/livros/liv97870.pdf

Vídeos e áudios

FANTÁSTICO - REPORTAGEM. Disponível em:

$<$ https://www.youtube.com/watch?v=Z_pUvdLbB2E>.

PODCAST DO B9. Disponível em: <http://www.b9.com.br/80827/mamilos-126-bullying/>.

SERGINHO GROISMAN ENTREVISTA ISABELA NICASTRO. Disponível em:

$<$ https://www.youtube.com/watch?v=pkduLIJgks0 >.

\section{Contato dos autores}

Karla Michelle de Meneses Caeiro Braga | kmmeneses05@gmail.com

Patrícia Marciano de Oliveira | pati.info.edu@gmail.com

Paula Jucá de Sousa | paulajuca@ifto.edu.br

Ana Paula Legey de Siqueira | asiqueira@unicarioca.edu.br 
Antônio Carlos Mól | amol@unicarioca.edu.br Victor Gonçalves Freitas | vfreitas@unicarioca.edu.br Leonardo Trotta | ltrotta@unicarioca.edu.br 